\title{
Focal salvage therapy for local prostate cancer recurrences after primary radiotherapy: a comprehensive review
}

\author{
D. A. Smit Duijzentkunst ${ }^{1}$ M. Peters ${ }^{1}$ (D) J. R. N. van der Voort van Zyp Z $^{1}$ \\ M. A. Moerland ${ }^{1}$ M. van Vulpen ${ }^{1}$
}

Received: 21 November 2015 / Accepted: 11 March 2016 / Published online: 24 March 2016

(C) The Author(s) 2016. This article is published with open access at Springerlink.com

\begin{abstract}
Background/Aim Patients with locally recurrent prostate cancer after primary radiotherapy can be eligible for salvage treatment. Whole-gland salvage techniques carry a high risk of toxicity. A focal salvage approach might reduce the risk of adverse events while maintaining cancer control in carefully selected patients. The aim of this review was to evaluate current literature to assess whether focal salvage leads to a comparable or favourable recurrence rate and less toxicity compared to whole-gland salvage.

Methods A literature search was performed using PubMed, Embase and the Cochrane Library. A total of 3015 articles were screened and assessed for quality. Eight papers [on focal cryoablation $(n=3)$, brachytherapy $(n=3)$ and high-intensity focused ultrasound $(n=2)$ ] were used to report outcomes.

Results One-, 2-, 3- and 5-year biochemical diseasefree survival (BDFS) ranges for focal salvage are, respectively, 69-100, 49-100, 50-91 and 46.5-54.5\%. Severe genitourinary, gastrointestinal and sexual function toxicity rates are $0-33.3 \%$. One study directly compares focal to whole-gland salvage cryotherapy, showing 5-year BDFS
\end{abstract}

D. A. Smit Duijzentkunst and M. Peters contributed equally to this research.

Electronic supplementary material The online version of this article (doi:10.1007/s00345-016-1811-9) contains supplementary material, which is available to authorized users.

M. Peters

M.Peters-10@umcutrecht.nl

1 Department of Radiation Oncology, University Medical Centre Utrecht, Q.02.2.314, Heidelberglaan 100, 3584 CX Utrecht, The Netherlands of, respectively, 54.4 and $86.5 \%$ with lower toxicity rates for focal salvage patients.

Conclusion Provisional data suggest that BDFS rates of focal salvage are in line with those of whole-gland approaches. There is evidence that focal salvage could decrease severe toxicity and preserve erectile function.

Keywords Prostate cancer - Radiorecurrent disease · Focal salvage $\cdot$ Iodine-125 brachytherapy $\cdot$ Cryotherapy . HIFU · Review

\section{Introduction}

Prostate cancer $(\mathrm{PCa})$ patients primarily treated with external beam radiotherapy (EBRT) or brachytherapy (BT) are at risk of a recurrence, depending on pretreatment characteristics. Intermediate- and high-risk groups can suffer from a biochemical recurrence in over $50 \%$ of the cases after 10-year follow-up [1]. Subsequently, they are at risk of developing metastases and dying of PCa [2]. Up to $98 \%$ of patients receive (palliative) androgen deprivation therapy (ADT) as treatment after a biochemical recurrence [3]. However, a substantial amount of patients harbour organ-confined disease eligible for a curative salvage procedure $[4,5]$, thereby preventing exposure of patients to the often severe side effects of ADT [6]. Salvage nowadays is usually performed using a whole-gland approach, which is accompanied by a high chance of severe gastrointestinal (GI), genitourinary (GU) and erectile toxicity due to previous radiation damage to surrounding organs at risk $[4,5]$. Given the evidence from pathology studies that recurrences are frequently localised at the site of the primary largest (index) tumour [7, 8], a focal salvage approach, directed solely at the area containing recurrent 
tumour, might be a viable treatment option for patients with unifocal PCa recurrences without metastatic disease. This way, serious adverse events associated with wholegland salvage might be prevented, while cancer control is maintained. The current literature regarding biochemical disease free survival (BDFS) and functional outcomes of focal salvage techniques for prostate cancer recurrences after primary radiotherapy is evaluated here.

\section{Materials and methods}

\section{Literature search}

On 19 August 2015, a systematic literature search was performed in the PubMed, Embase and Cochrane Library databases. In order to create a sensitive search, the search syntax was build based on domain and determinant (Table 1). After removal of duplicates, 3015 papers were screened, selecting 55 articles with matching domain and determinant. Exclusion criteria are listed in the flow chart (Fig. 1). An additional reference search was performed, resulting in 12 studies for this review [9-20].

Table 1 Search syntax

\begin{tabular}{llll}
\hline $\begin{array}{l}\text { All search terms (title/abstract) for PubMed, (ab,ti) for Embase and } \\
\text { (:ti,ab,kw) for Cochrane }\end{array}$ & 14 & Local \\
\hline 1 & Salvage & 15 & Focal \\
2 & Therapy & 16 & Prostate \\
3 & Treatment & 17 & Prostatic \\
4 & Rescue & 18 & Cancer \\
5 & Cryoablation & 19 & Carcinoma \\
6 & Cryosurgery & 20 & Adenocarcinoma \\
7 & Cryotherapy & 21 & Neoplasma \\
8 & Ablation & 22 & Recurrence \\
9 & Brachytherapy & 23 & Recurrences \\
10 & HIFU & 24 & Recurrent \\
11 & 'high-intensity focused ultrasound' & 25 & Relapse \\
12 & Hemi & 26 & Radiorecurrent \\
13 & Partial & & \\
27 & 1 or 2 or 3 or 4 or 5 or 6 or 7 or 8 or 9 or & & \\
& 10 or 11 & & \\
28 & 12 or 13 or 14 or 15 & & \\
29 & 27 and 28 & Total: 4729 \\
30 & 16 or 17 & & \\
31 & 18 or 19 or 20 or 21 & PubMed: 1719 \\
32 & 22 or 23 or 24 or 25 or 26 & Embase: 2811 \\
33 & 30 and 31 and 32 & Cochrane: 199 \\
34 & 29 and 33 & & \\
\hline & & & \\
& & & \\
& & & \\
& &
\end{tabular}

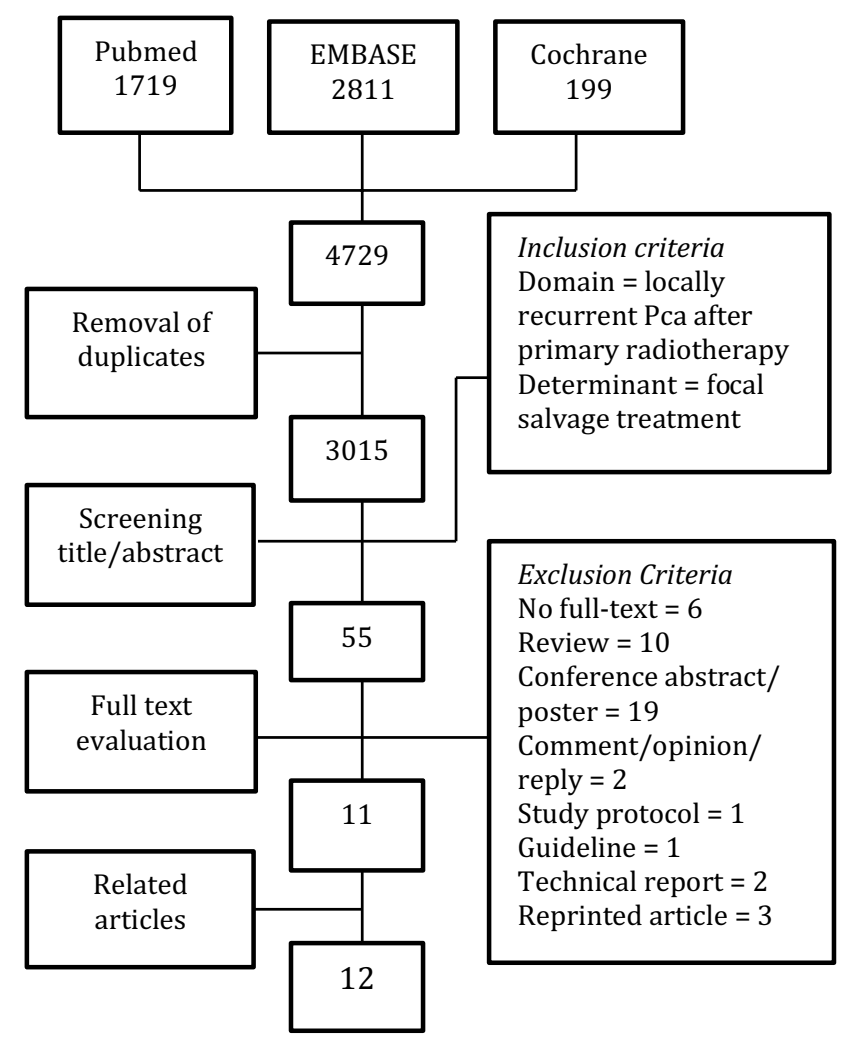

Fig. 1 Flow chart

\section{Study selection}

Studies were subjected to a critical appraisal based on an adaptation of the Dutch Cochrane Centre recommendations (ACROBAT-NRSI risk of bias assessment tool) [21]. Studies were graded $(+),( \pm)$ or $(-)$ on relevance (domain, determinant, outcome) and validity (selection, study population characteristics, exposure, primary outcome, secondary outcomes, follow-up and number of patients) [Table A1 (supplementary file)].

All studies were observational cohorts or case series with either prospective or retrospective data acquisition. Therefore, no study could be considered of high quality. Blinding was applied in none of the studies (not graded). However, the primary outcome (BDFS) is unlikely to be influenced by information bias, due to the objectivity of the failure definition (Phoenix, i.e. PSA-nadir $+2.0 \mathrm{ng} / \mathrm{ml}$ ). On the contrary, the toxicity assessment is subjective to information bias and is graded in that way.

Confounding was not graded, since all studies except one were single-arm observational cohorts. The study by De Castro et al. [9] describes a two-armed cohort. Here, possible confounding factors are adequately described, but not corrected for in multivariable analysis.

Four studies describe case series $\leq 10$ patients $[12,13$, $19,20]$. These were valued as low quality and excluded. 


\section{Results}

\section{Search results}

A total of eight studies were eligible for data extraction, describing focal salvage treatment with cryoablation (CA) $(n=3)[9,14,16]$, low-dose-rate brachytherapy (LDR-BT) $(n=3)[15,17,18]$ and high-intensity focused ultrasound (HIFU) $(n=2)[10,11]$ in 278 patients. Table 2 shows study characteristics. Studies used a salvage approach on a focal lesion (quadrant ablation by Ahmed et al. [10] and clinical target volume of approximately $17 \%$ by Hsu et al. [15]), one half of the prostate (hemi) or a partial approach (area not specified by Li et al. [16] and Eisenberg et al. [14]). Nguyen et al. [17] describe LDR-BT to the entire peripheral zone. In all studies, ADT use was discontinued at time of enrolment.

\section{Diagnosis of focality}

All recurrences were initially detected by PSA measurement (biochemical failure), verified with prostate biopsies. The diagnostic modalities used to determine the recurrence location differed. Available specifics are described here.

Five studies used magnetic resonance imaging (MRI). Ahmed et al. [10] describe the use of a multiparametric approach: T2-weighted (T2 W), diffusion-weighted (DW) and dynamic contrast-enhanced (DCE) 1.5-Tesla (T) MRI. Results were combined with transrectal ultrasound (TRUS)-guided or transperineal template prostate mapping (TPM) biopsies ( $n=19$ and $n=20$, respectively). Baco et al. [11] describe the use of T2 W, DW and DCE 3T MRI in 27 and T2 W and DW 1.5T MRI in 21 patients. Imaging results were verified a mean 15 cores TRUS-guided biopsies (sd 10, range 7-60). Peters et al. [18] describe the use of T1 W, T2 W, DWI and DCE 3T MRI, verified with systematic transrectal biopsies (median 10 cores, range 6-13). Sequences are not specified in the studies of Nguyen et al. [17] and Hsu et al. [15], though the latter did perform MR spectroscopy and acquired TRUS-guided biopsy confirmation of disease. Both do not define the amount of biopsy cores taken.

De Castro Abreu et al. [9] treated the tumour volume based on both systematic and lesion-targeted TRUS-guided biopsies and hypo-echogenic lesions on TRUS. Eisenberg et al. [14] treated based on 16-core sample TRUS-guided biopsy. Li et al. [16], using the Cryo On-Line Data (COLD) registry, do not describe any diagnostic modality used to define the location of the recurrence or (PSA-based) selection method.

\section{Exclusion of metastatic disease}

Three studies used positron emission tomography (PET) in excluding metastatic disease (Ahmed et al. [10], Baco et al. [11] and Peters et al. [18]). Ahmed et al. [10] used a combination of pelvic MRI, a radioisotope bone scan and 18-fluorodeoxyglucose (FDG) PET/CT in all patients for the assessment of metastatic disease (bone and lymph node). Baco et al. [11] used a combination of bone scan and pelvic CT or MRI. 11C-Choline PET was used in 27 of 42 patients. Peters et al. also use a bone scan and pelvis CT or MRI, but used 18F-Choline PET in 10 of the 20 patients.

\section{Biochemical disease-free survival}

Results on BDFS are also shown in Table 2. Biochemical failure was defined according to the Phoenix (PSAnadir $+2 \mathrm{ng} / \mathrm{ml}$ ) or ASTRO definition (three consecutive post-nadir rises in PSA, with the moment of failure backdated between the nadir and the first rise). BDFS ranges at $1,2,3$ and 5 years are, respectively, 69-100, 49-100, 50-91 and 46.5-54.4\%. The studies with an MRI-based assessment of focal disease had BDFS of $49-100 \%$ up to 2-3 years compared to $72.4-79 \%$ for non-MRI-based focal salvage series. The only 5-year Kaplan-Meier estimates come from the study by de Castro-Abreu et al. [9] and Li et al. [16], who do not use MRI for intraprostatic disease assessment or PET for exclusion of metastatic disease (de Castro-Abreu et al. [9]) or do not specify the assessment (Li et al. [16]). They provide BDFS of $46.5 \%$ (Li et al. [16]) and $54.4 \%$ (de Castro-Abreu et al. [9]).

\section{Toxicity}

Toxicity results are shown in Table 3 for various measurement methods. CTCAE grades indicate (1) toxicity without (the need for) intervention, (2) requiring medication, (3) requiring inpatient or outpatient surgical intervention, (4) requiring ICU admission and (5) death. No grade 4 or 5 toxicity was reported. Higher IPSS (prostate symptoms), lower IIEF (erectile function) and lower QLQ C-30 (quality of life) indicate deterioration. In addition, Ahmed et al. [10] reported surgical complications according to the modified Clavien system, showing the need for intervention under local (grade 3a) or general (grade 3b) anaesthesia in, respectively, $1(3 \%)$ and $9(23 \%)$ patients. Nguyen et al. [17] reported outcomes according to the Radiation Therapy Oncology Group/Late Effects Normal Tissue Task Force criteria, showing rectal bleeding in $2(8 \%)$, urethral stricture in $1(4 \%)$, periprostatic abscess in $1(4 \%)$ and prostate-rectal fistula in $3(12 \%)$ patients. 


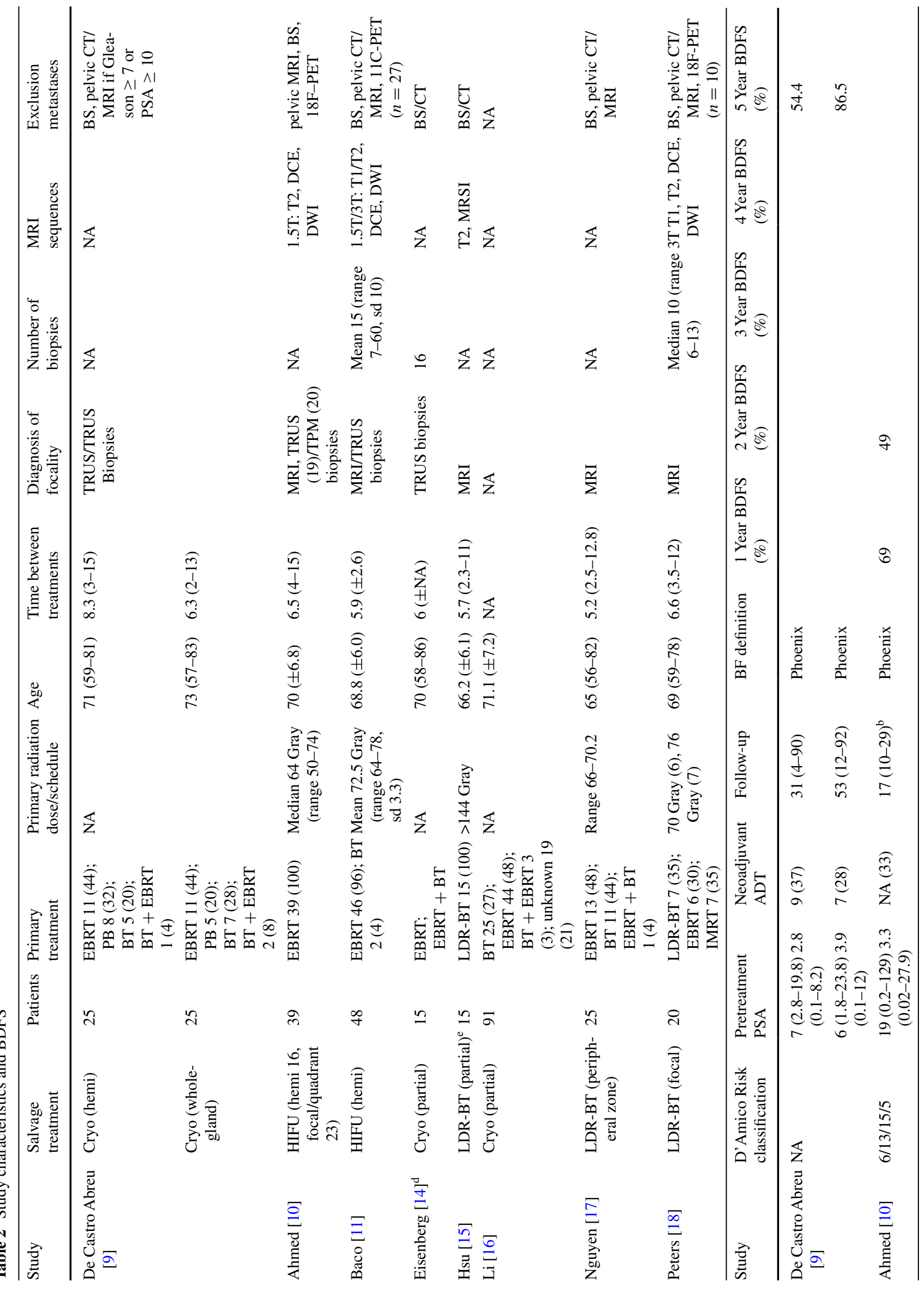




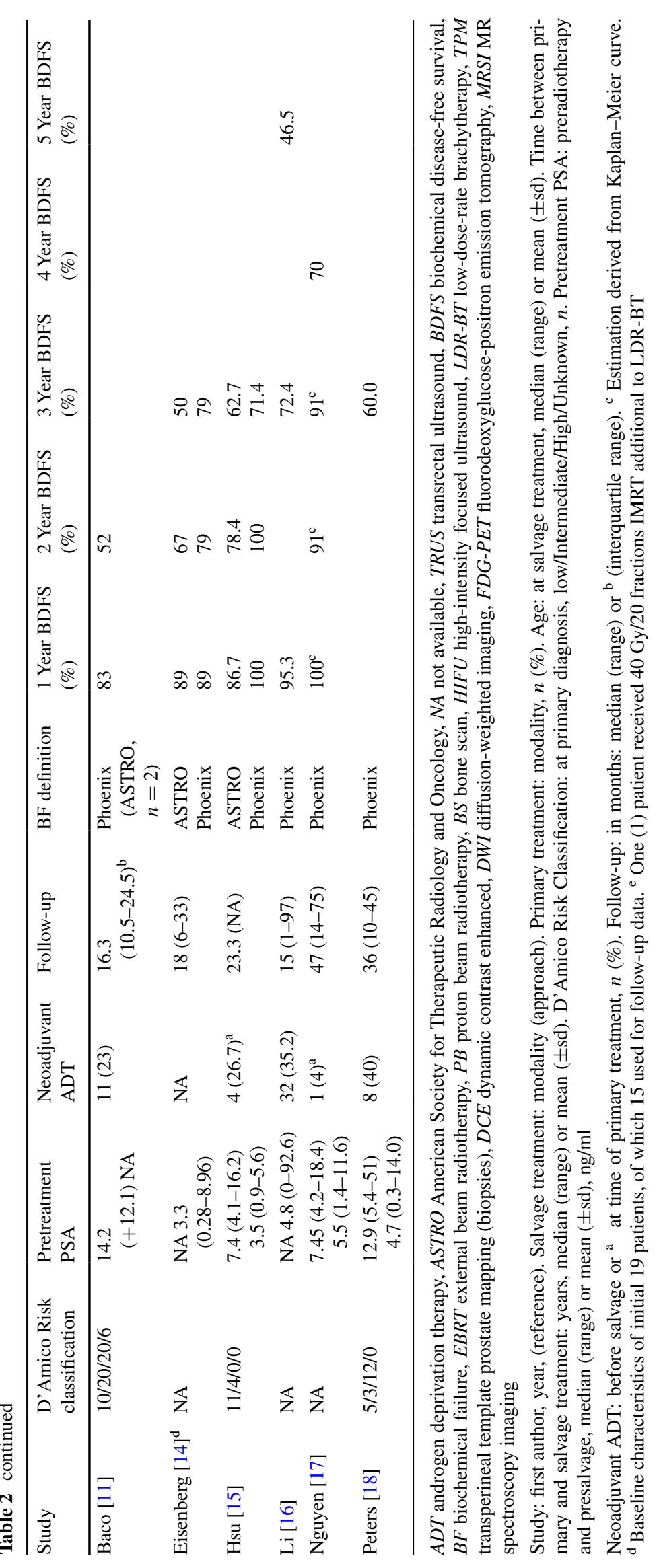


Table 3 Toxicity

\begin{tabular}{|c|c|c|c|}
\hline Study & $\begin{array}{l}\text { New CTCAE } \\
\text { GU Toxicity grade } \geq 2\end{array}$ & $\begin{array}{l}\text { New CTCAE } \\
\text { GI Toxicity grade } \geq 2\end{array}$ & $\begin{array}{l}\text { New CTCAE SF } \\
\text { Toxicity grade } \geq 2\end{array}$ \\
\hline Hsu & $4(26.7)$ & $0(0)$ & $4(26.7)$ \\
\hline Peters & $6(33.3)$ & $0(0)$ & $0(0)$ \\
\hline Study & New Clavien Toxicity grade $\geq 2$ & \multicolumn{2}{|c|}{ New late RTOG Toxicity grade $\geq 3$} \\
\hline Ahmed & $10(30)$ & & \\
\hline Nguyen & \multicolumn{3}{|c|}{$7(28)$} \\
\hline Study & IPSS before/at last FU & IIEF before/at last FU & $\begin{array}{l}\text { QLQ C-30 before/ } \\
\text { at last FU }\end{array}$ \\
\hline Ahmed & $10.1 / 13$ & $18 / 13^{\mathrm{a}}$ & \\
\hline Baco & 7.1/8.6 & $11.2 / 7.0$ & $35.7 / 36.8$ \\
\hline Study & New incontinence & New urethral toxicity & Potency before/after salvage \\
\hline De Castro Abreu (focal vs. total) & 0 versus 3 (0 vs. 12$)$ & 0 versus 1 (0 vs. 4$)$ & $7 / 2$ versus $4 / 0(28 / 8$ vs. $16 / 0)$ \\
\hline Eisenberg & $1(6.7)$ & $2(13.3)$ & \\
\hline $\mathrm{Li}$ & $5(5.5)$ & $3(3.3)$ & $20 / 10(21.2 / 11)$ \\
\hline
\end{tabular}

CTCAE Common Terminology Criterial for Adverse Events, $G U$ genitourinary, $G I$ gastrointestinal, $S F$ sexual function, $R T O G$ radiation therapy oncology group, IPSS International Prostate Symptoms Score, IIEF International Index of Erectile Function, $Q L Q C 30$ European Organisation for the Research and Treatment of Cancer Quality of Life Questionnaire, $F U$ follow-up

Toxicity rates in numbers $(\%)$

Questionnaire results: mean or ${ }^{\text {a }}$ median. Urethral toxicity: strictures, ulcers and recto-urethral fistulae formation

Both Hsu et al. [15] and Peters et al. [18] report no new $\geq$ grade 2 GI toxicity in the late phase ( $>3-6$ months). Hsu et al. [15] report on five patients with $\geq$ grade 2 GU toxicity requiring medication. Furthermore, two patients developed new medication-resistant erectile dysfunction (ED, grade 3) and two patients medication-responsive ED. Peters et al. [18] report one patient $(5 \%)$ with a grade 3 urethral stricture, requiring endoscopic incision. One patients suffered from radiation cystitis grade 2 , managed with hyperbaric oxygen therapy. Five more patients had grade 2 urinary frequency, managed with medication. No new erectile dysfunction (ED) was seen in the five previously potent patients. Furthermore, a significant decrease in the EORTC-PR25 urinary symptoms quality-of-life $(\mathrm{QoL})$ domain after a median of 3 years was observed.

Functional deterioration was also observed in symptom scales used by Baco et al. [11] and Ahmed et al. [10]. An International Prostate Symptom Score (IPSS) increase from 7.1 to $8.6(p=0.13)$ and 10.1 to 13 (no $p$ value) was seen, respectively. Furthermore, International Index of Erectile Function (IIEF) decreased from mean 11.2 to $8(p<0.001)$ and median 18 to 13 (no $p$ value), respectively. Baco et al. [11] do not notice a significant decrease in EORTC QLQC30 score: $35.7-36.8(p=0.22)$.

Eisenberg et al. [14] describe the occurrence of one mild stress incontinence (grade not given), one urethral stricture requiring dilation and one prostatic urethral ulcer managed with suprapubic catheter drainage. Two out of five patients remained potent. Li et al. [16] describe $5(5.5 \%)$ patients requiring pad-use at 12 months and $3(3.3 \%)$ recto-urethral fistulas. Half of the patients retained potency, although medication was not specified.

A subdivision in more focally targeted ablation and studies using MRI-assessment for recurrences was not made due to (most importantly) the unavailability of salvage extent.

\section{Discussion}

\section{Comparing focal to whole-gland salvage}

The aim of this study was to assess whether focal salvage for local prostate cancer recurrences after primary radiotherapy leads to a comparable or favourable recurrence rate and less toxicity compared to whole-gland salvage. De Castro Abreu et al. [9] present the only study comparing focal to whole-gland salvage cryotherapy. Recurrences were not verified by MR imaging. BF occurred in $32 \%$ (focal) and $12 \%$ (whole-gland), resulting in 5-year Kaplan-Meier BDFS estimates of, respectively, 54.4 and $86.5 \%$. This could be an indication that focal salvage patients are undertreated or that the relation is confounded 


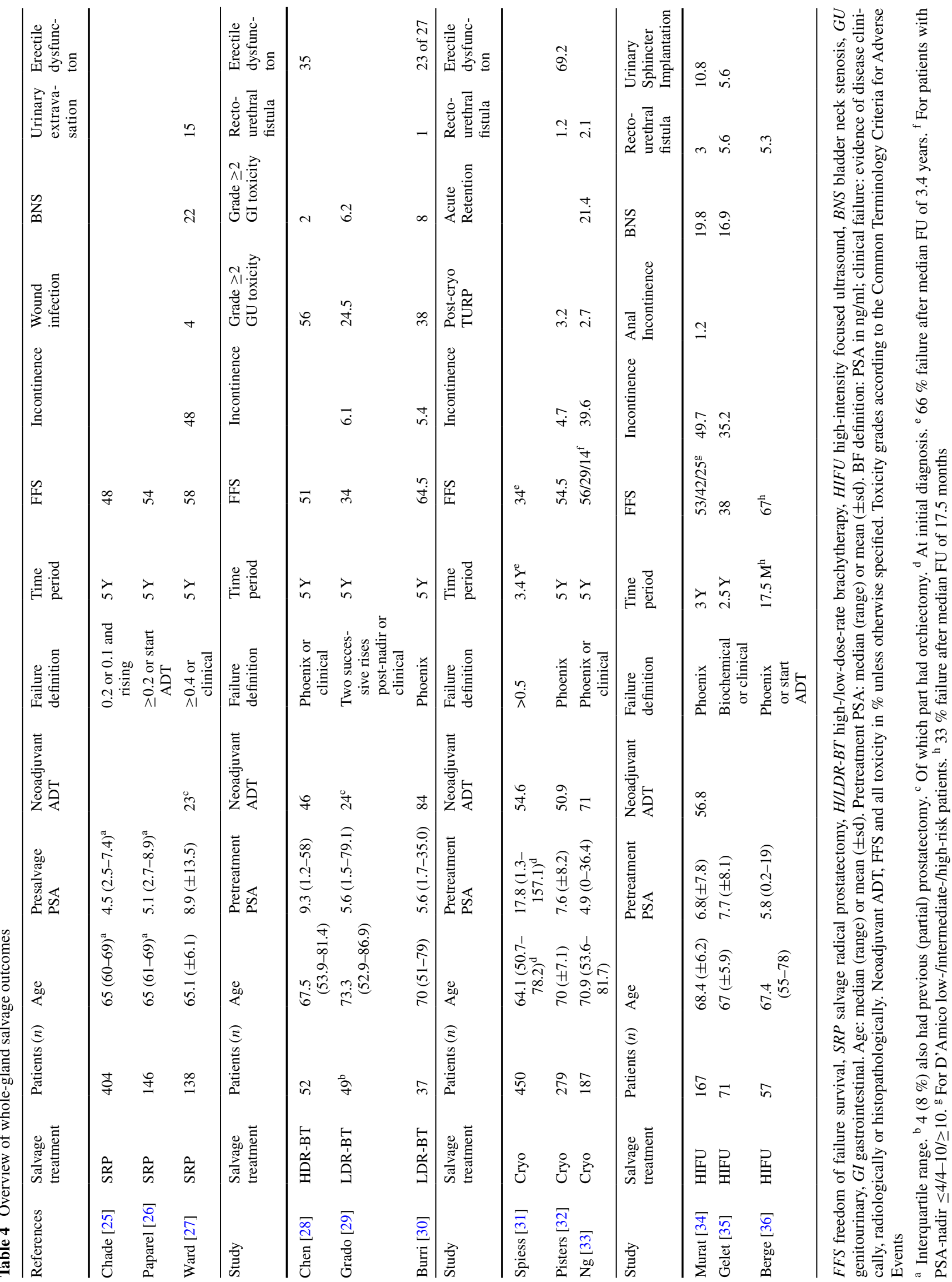


by other factors related to BF. Since recurrences were not assessed by MRI or TPM biopsies, focal salvage patients might have been under assessed. Furthermore, the comparison indicates that focal salvage might be less toxic: no focal salvage patients developed incontinence or recto-urethral fistula versus 3 and 1 , respectively. Furthermore, two focal salvage patients retained potency, versus none in the total salvage group. However, these numbers were small and statistical significance was not achieved. This comparison between the two ablation methods is hampered by differences in primary radiation schedules/modalities, the extend of focal salvage and differences in patient characteristics.

Whole-gland salvage outcomes are shown in Table 4. Systematic reviews on salvage therapies for radiorecurrent PCa [5, 22, 23] and the European Association of Urology (EAU) guideline [24] were searched to select the three largest studies of the four common salvage therapies (salvage radical prostatectomy (SRP) [25-27], BT [28-30], CA [31-33] and HIFU [34-36]). These publications do not provide recommendations on the type of whole-gland salvage treatment to use.

Focal salvage BDFS rates (1, 2, 3, 5 years, respectively, 69-100, 49-100, 50-72.4 and 46.5-54.4\%) are in line with BDFS outcomes reported for whole-gland salvage. The largest SRP and CA studies show 5-year freedom of failure survival (FFS) rates of, respectively, 48-58 and 54.5-56\%.

Notable results outside these ranges are reported by Spiess et al. [31], describing 450 whole-gland salvage CA patients, with $66 \%$ failure after median follow-up of 3.4 years. Grado et al. [29] describe 49 patients treated with BT, with a 5-year FFS of $34 \%$. Contrary to these results, Burri et al. [30] describe 37 patients treated with BT, with a 5-year FFS of $64.5 \%$.

In addition to reported results, Wenske et al. [37] describe a cohort of 55 focal CA patients after primary radiotherapy $(80 \%)$ or CA $(20 \%)$. There is no stratification for primary therapy. Reported 5-year BDFS (Phoenix definition) is $47 \%$. Bladder outlet obstruction occurred in $1.8 \%$ and fistula formation in $5.5 \%$ of patients.

Toxicity of focal approaches is comparable to or favourable compared to whole-gland salvage. Fistula rates are low across all studies. Notable results are reported by $\mathrm{Hsu}$ et al. [15] describing 15 focal salvage BT patients. There was no new GI toxicity and no new incontinence. Potency (medication assisted) was preserved in 13/15. Peters et al. [18] report preserved potency in the five previously potent patients. Potency is sparsely reported in SRP cohorts. From the assessed reviews, two SRP studies were retrieved describing SF. Masterson et al. [38] report preserved (medication assisted) potency in 6/40 (15\%), Boris et al. [39] in $2 / 10(20 \%)$.

\section{Limitations}

\section{Recurrent disease}

Biochemical recurrences in prostate cancer often seem to stem from a localised process. Data on the exact location are scarce, but it is suggested that the tumour often recurs at the site of the primary dominant or 'index lesion' [7, 8, 40, 41]. The evidence is not unanimous, however, with tumour regrowth frequently occurring multifocally in some studies, although organ-confined and unifocal disease remains being observed [42, 43]. Also, radical prostatectomy or TPM biopsies are sometimes not used as the reference standard [7, 40], thereby possibly giving an overestimation of local recurrences. The studies which use pathology as the reference standard usually identify less unifocal disease localisation [42, 43]. However, in these studies patients were often treated with lower doses of radiation than with current dose escalation. A recent large analysis by Zumsteg et al. [1] in which 2.694 patients were treated with IMRT with a total dose $\geq 79.2$ Gy (maximal 85.6 Gy) shows that biochemical recurrences are still common. Estimated 8-year recurrence rates of 9.7, 22.7 and $43.9 \%$ for low, intermediate and high National Cancer Comprehensive Network (NCCN) risk groups was observed. It might be that with these dose schedules, secondary tumour foci are increasingly successfully treated. This could mean that radiorecurrent disease is shifting towards the index lesion and theoretically more patients in the future can be eligible for focal salvage. In addition, even though cancer control rates are increasing with further dose escalation, ADT use and enhanced patient selection, there will be an increase in absolute numbers of patients with biochemical recurrent disease because more patients are primarily treated with radiotherapy. The stage migration to lower risk disease due to PSA screening could lead to more recurrences originating from increasingly lower risk disease, which is possibly more often localised and unifocal.

\section{Study limitations}

Reporting outcomes and comparing studies is significantly limited by several factors. The primary limitation is the lack of randomised controlled trials. All studies found are observational cohorts or case series. Selection of a more favourable or motivated patient population is a possibility in these focal salvage groups, thereby possibly biasing the comparison between focal and whole-gland salvage and between focal salvage modalities in terms of cancer control and toxicity. Furthermore, the lack of blinding in all studies could have biased especially toxicity assessment, both on patient and physician level. 
Secondly, a straightforward comparison of studies is difficult. There is no international consensus on the definition of failure. Although there is a tendency to report BDFS according to the Phoenix definition (used in all focal salvage studies), there is a wide variety of failure definitions, including combined biochemical and clinical (physical, radiological, histopathological) proof of disease. Gelet et al. [35] report a $73 \%$ negative biopsy rate at 30 months; however, combining biopsy results with biochemical results and need for ADT, the disease-free rate drops to $38 \%$. In reporting toxicity outcomes, there is little consistency as well.

In addition, diagnostic modalities for the assessment of recurrences and the exclusion of metastases vary. Only Ahmed et al. [10], Peters et al. [18] and Baco et al. [11] use PET in all, 10 and 27 patients, respectively, to exclude metastatic disease. PET has increased accuracy in assessing lymph node and distant metastases over technetium-99 scintigraphy and/or CT/MRI [44-46]. This could have contributed to more favourable outcomes in terms of cancer control and could possibly lead to a further increase in the future if these modalities become the diagnostic standard. Also, new biopsy techniques could lead to a further increase in the assessment of a focal recurrence, without missing possible significant multifocal recurrent disease. TPM biopsies could lead to increased accuracy over systematic TRUS-guided biopsies alone, while MRI-guided biopsies might decrease the detection of insignificant disease further [47, 48]. However, TPM biopsies were only adopted by Ahmed et al. [10], and MRI-guided biopsies by Baco et al. [11]. The other studies used different TRUSguided schedules, thereby possibly undertreating the prostate with a focal salvage approach.

Finally, study populations are relatively small, limiting power, and follow-up is relatively short, limiting the number of outcome events and thereby an accurate estimation of BDFS proportions and late toxicity.

\section{Future trials}

When considering trials for salvage modalities, willingness for randomisation is essential. This has been extremely problematic in a randomised study comparing prostatectomy and brachytherapy [49]. This accrual problem was also present in the PIVOT trial, in which only $15 \%$ of patients were randomised [50]. Increasing favourable data from focal salvage studies (e.g. from the recently started FORECAST trial [Focal Recurrent Assessment and Salvage Treatment for Radiorecurrent Prostate Cancer] [51]) might further decrease the willingness for randomisation in potential future head to head salvage trials.

A solution can possibly be found in the cohort multiple randomised controlled trial (cmRCT) design [52]. In this study design, all patients with radiorecurrent disease (or all prostate cancer patients) in a centre would be included into a cohort. With consent, these patients can in the future be randomised into experimental and control groups when a new treatment becomes available, providing the standard of care to the control group and, after additional consent, a new modality to the experimental group. This could provide unbiased comparisons between salvage procedures and possibly even between salvage ablation modalities, without the need for substantial resources to achieve sufficient accrual.

\section{Conclusion}

In this review of studies on focal salvage therapies, provisional data suggest that BDFS rates after focal salvage are in line with those of whole-gland approaches. There is evidence that focal salvage could decrease severe toxicity and preserve erectile function. Based on these results, focal salvage can be considered a viable option for unifocal prostate cancer recurrences after primary radiotherapy in properly selected patients. For further research, there is a great need for randomised controlled trials comparing salvage ablation methods and possibly even modalities. These trials would need to be uniform regarding patient selection and in outcome assessment and reporting. Lastly, relevant endpoint (mortality) assessed after sufficient follow-up are preferred over proxy outcomes such as biochemical failure.

Authors' contribution Smit Duijzentkunst, Peters, van der Voort van Zyp, Moerland and van Vulpen all contributed to protocol/project development, data collection or management, data analysis and writing/editing of the manuscript.

\section{Compliance with ethical standards}

Conflict of interest The authors declare no conflict of interests in relation to this study.

Open Access This article is distributed under the terms of the Creative Commons Attribution 4.0 International License (http://creativecommons.org/licenses/by/4.0/), which permits unrestricted use, distribution, and reproduction in any medium, provided you give appropriate credit to the original author(s) and the source, provide a link to the Creative Commons license, and indicate if changes were made.

\section{References}

1. Zumsteg ZS, Spratt DE, Romesser PB et al (2015) The natural history and predictors of outcome following biochemical relapse in the dose escalation era for prostate cancer patients undergoing definitive external beam radiotherapy. Eur Urol 67(6):10091016. doi:10.1016/j.eururo.2014.09.028 
2. Zhou P, Chen MH, McLeod D, Carroll PR, Moul JW, D'Amico AV (2005) Predictors of prostate cancer-specific mortality after radical prostatectomy or radiation therapy. J Clin Oncol 23(28):6992-6998

3. Tran H, Kwok J, Pickles T, Tyldesley S, Black PC (2014) Underutilization of local salvage therapy after radiation therapy for prostate cancer. Urol Oncol 32(5):701-706. doi:10.1016/j. urolonc.2013.12.014

4. Alongi F, De Bari B, Campostrini F et al (2013) Salvage therapy of intraprostatic failure after radical external-beam radiotherapy for prostate cancer: a review. Crit Rev Oncol Hematol 88(3):550-563. doi:10.1016/j.critrevonc.2013.07.009

5. Nguyen PL, D'Amico AV, Lee AK, Suh WW (2007) Patient selection, cancer control, and complications after salvage local therapy for postradiation prostate-specific antigen failure: a systematic review of the literature. Cancer 110(7):1417-1428. doi:10.1002/cncr.22941

6. Nguyen PL, Alibhai SM, Basaria S et al (2015) Adverse effects of androgen deprivation therapy and strategies to mitigate them. Eur Urol 67(5):825-836. doi:10.1016/j.eururo.2014.07.010

7. Cellini N, Morganti AG, Mattiucci GC et al (2002) Analysis of intraprostatic failures in patients treated with hormonal therapy and radiotherapy: implications for conformal therapy planning. Int J Radiat Oncol Biol Phys 53(3):595-599

8. Pucar D, Hricak H, Shukla-Dave A et al (2007) Clinically significant prostate cancer local recurrence after radiation therapy occurs at the site of primary tumor: magnetic resonance imaging and step-section pathology evidence. Int J Radiat Oncol Biol Phys 69(1):62-69

9. de Castro Abreu AL, Bahn D, Leslie S et al (2013) Salvage focal and salvage total cryoablation for locally recurrent prostate cancer after primary radiation therapy. BJU Int 112(3):298-307. doi:10.1111/bju.12151

10. Ahmed HU, Cathcart P, McCartan N et al (2012) Focal salvage therapy for localized prostate cancer recurrence after external beam radiotherapy: a pilot study. Cancer 118(17):4148-4155. doi: $10.1002 /$ cncr. 27394

11. Baco E, Gelet A, Crouzet S et al (2014) Hemi salvage highintensity focused ultrasound (HIFU) in unilateral radiorecurrent prostate cancer: a prospective two-centre study. BJU Int 114(4):532-540. doi:10.1111/bju.12545

12. Bomers JG, Yakar D, Overduin CG et al (2013) MR imagingguided focal cryoablation in patients with recurrent prostate cancer. Radiology 268(2):451-460. doi:10.1148/radiol.13121291

13. Chang L, Buyyounouski MK (2014) Salvage low-dose-rate (125)I partial prostate brachytherapy after dose-escalated external beam radiotherapy. J Contemp Brachyther 6(3):304-310. doi:10.5114/jcb.2014.45134

14. Eisenberg ML, Shinohara K (2008) Partial salvage cryoablation of the prostate for recurrent prostate cancer after radiotherapy failure. Urology 72(6):1315-1318. doi:10.1016/j. urology.2008.03.040

15. Hsu CC, Hsu H, Pickett B et al (2013) Feasibility of MR imaging/MR spectroscopy-planned focal partial salvage permanent prostate implant (PPI) for localized recurrence after initial PPI for prostate cancer. Int J Radiat Oncol Biol Phys 85(2):370-377. doi:10.1016/j.ijrobp.2012.04.028

16. Li YH, Elshafei A, Agarwal G, Ruckle H, Powsang J, Jones JS (2015) Salvage focal prostate cryoablation for locally recurrent prostate cancer after radiotherapy: initial results from the cryo on-line data registry. Prostate 75(1):1-7. doi:10.1002/pros.22881

17. Nguyen PL, Chen MH, D'Amico AV et al (2007) Magnetic resonance image-guided salvage brachytherapy after radiation in select men who initially presented with favorable-risk prostate cancer: a prospective phase 2 study. Cancer 110(7):1485-1492. doi:10.1002/cncr.22934
18. Peters M, Maenhout M, Der Voort Van, Van Zyp JRN et al (2014) Focal salvage iodine-125 brachytherapy for prostate cancer recurrences after primary radiotherapy: a retrospective study regarding toxicity biochemical outcome and quality of life. Radiother Oncol 112(1):77-82

19. Sasaki H, Kido M, Miki K et al (2014) Salvage partial brachytherapy for prostate cancer recurrence after primary brachytherapy. Int J Urol 21(6):572-577. doi:10.1111/iju.12373

20. Shariat SF, Raptidis G, Masatoschi M, Bergamaschi F, Slawin KM (2005) Pilot study of radiofrequency interstitial tumor ablation (RITA) for the treatment of radio-recurrent prostate cancer. Prostate 65(3):260-267

21. Sterne JAC, Higgins JPT, Reeves BC. A cochrane risk of bias assessment tool: For non-randomized studies of interventions (ACROBAT-NRSI), version 1.0.0. http://www.riskofbias.info. Updated 2014. Accessed 19 Aug 2014

22. Kimura M, Mouraviev V, Tsivian M, Mayes JM, Satoh T, Polascik TJ (2010) Current salvage methods for recurrent prostate cancer after failure of primary radiotherapy. BJU Int 105(2):191201. doi:10.1111/j.1464-410X.2009.08715.x

23. Parekh A, Graham PL, Nguyen PL (2013) Cancer control and complications of salvage local therapy after failure of radiotherapy for prostate cancer: a systematic review. Semin Radiat Oncol 23(3):222-234. doi:10.1016/j.semradonc.2013.01.006

24. Mottet N, Bellmunt J., Briers E, et al. European association of urology (EAU) prostate cancer guideline. http://uroweb.org/wpcontent/uploads/EAU-Guidelines-Prostate-Cancer-2015-v2.pdf. Updated 2015. Accessed 14 Aug 2015

25. Chade DC, Shariat SF, Cronin AM et al (2011) Salvage radical prostatectomy for radiation-recurrent prostate cancer: a multi-institutional collaboration. Eur Urol 60(2):205-210. doi:10.1016/j.eururo.2011.03.011

26. Paparel P, Cronin AM, Savage C, Scardino PT, Eastham JA (2009) Oncologic outcome and patterns of recurrence after salvage radical prostatectomy. Eur Urol 55(2):404-410. doi:10.1016/j.eururo.2008.07.007

27. Ward JF, Sebo TJ, Blute ML, Zincke H (2005) Salvage surgery for radiorecurrent prostate cancer: contemporary outcomes. J Urol 173(4):1156-1160

28. Chen CP, Weinberg V, Shinohara K et al (2013) Salvage HDR brachytherapy for recurrent prostate cancer after previous definitive radiation therapy: 5-year outcomes. Int J Radiat Oncol Biol Phys 86(2):324-329. doi:10.1016/j.ijrobp.2013.01.027

29. Grado GL, Collins JM, Kriegshauser JS et al (1999) Salvage brachytherapy for localized prostate cancer after radiotherapy failure. Urology 53(1):2-10

30. Burri RJ, Stone NN, Unger P, Stock RG (2010) Long-term outcome and toxicity of salvage brachytherapy for local failure after initial radiotherapy for prostate cancer. Int J Radiat Oncol Biol Phys 77(5):1338-1344. doi:10.1016/j.ijrobp.2009.06.061

31. Spiess PE, Katz AE, Chin JL et al (2010) A pretreatment nomogram predicting biochemical failure after salvage cryotherapy for locally recurrent prostate cancer. BJU Int 106(2):194-198. doi:10.1111/j.1464-410X.2009.09078.x

32. Pisters LL, Rewcastle JC, Donnelly BJ, Lugnani FM, Katz AE, Jones JS (2008) Salvage prostate cryoablation: Initial results from the cryo on-line data registry. J Urol 180(2):559-563. doi:10.1016/j.juro.2008.04.005 (discussion 563-4)

33. Ng CK, Moussa M, Downey DB, Chin JL (2007) Salvage cryoablation of the prostate: Followup and analysis of predictive factors for outcome. J Urol 178(4 Pt 1):1253-1257 (discussion 1257)

34. Murat FJ, Poissonnier L, Rabilloud M et al (2009) Mid-term results demonstrate salvage high-intensity focused ultrasound (HIFU) as an effective and acceptably morbid salvage treatment 
option for locally radiorecurrent prostate cancer. Eur Urol 55(3):640-647. doi:10.1016/j.eururo.2008.04.091

35. Gelet A, Chapelon JY, Poissonnier L et al (2004) Local recurrence of prostate cancer after external beam radiotherapy: early experience of salvage therapy using high-intensity focused ultrasonography. Urology 63(4):625-629. doi:10.1016/j. urology.2004.01.002

36. Berge V, Baco E, Dahl AA, Karlsen SJ (2011) Health-related quality of life after salvage high-intensity focused ultrasound (HIFU) treatment for locally radiorecurrent prostate cancer. Int J Urol 18(9):646-651. doi:10.1111/j.1442-2042.2011.02815.x

37. Wenske S, Quarrier S, Katz AE (2013) Salvage cryosurgery of the prostate for failure after primary radiotherapy or cryosurgery: long-term clinical, functional, and oncologic outcomes in a large cohort at a tertiary referral centre. Eur Urol 64(1):1-7. doi:10.1016/j.eururo.2012.07.008

38. Masterson TA, Stephenson AJ, Scardino PT, Eastham JA (2005) Recovery of erectile function after salvage radical prostatectomy for locally recurrent prostate cancer after radiotherapy. Urology 66(3):623-626

39. Boris RS, Bhandari A, Krane LS, Eun D, Kaul S, Peabody JO (2009) Salvage robotic-assisted radical prostatectomy: initial results and early report of outcomes. BJU Int 103(7):952-956. doi:10.1111/j.1464-410X.2008.08245.x

40. Arrayeh E, Westphalen AC, Kurhanewicz J et al (2012) Does local recurrence of prostate cancer after radiation therapy occur at the site of primary tumor? results of a longitudinal MRI and MRSI study. Int J Radiat Oncol Biol Phys 82(5):e787-e793. doi:10.1016/j.ijrobp.2011.11.030

41. Menard C, Iupati D, Publicover J et al (2015) MR-guided prostate biopsy for planning of focal salvage after radiation therapy. Radiology 274(1):181-191. doi:10.1148/radiol.14122681

42. Huang WC, Kuroiwa K, Serio AM et al (2007) The anatomical and pathological characteristics of irradiated prostate cancers may influence the oncological efficacy of salvage ablative therapies. J Urol 177(4):1324-1329 (quiz 1591)

43. Leibovici D, Chiong E, Pisters LL et al (2012) Pathological characteristics of prostate cancer recurrence after radiation therapy: implications for focal salvage therapy. J Urol 188(1):98-102. doi:10.1016/j.juro.2012.02.2571
44. Evangelista L, Zattoni F, Guttilla A et al (2013) Choline PET or PET/CT and biochemical relapse of prostate cancer: a systematic review and meta-analysis. Clin Nucl Med 38(5):305-314. doi:10.1097/RLU.0b013e3182867f3c

45. Evangelista L, Guttilla A, Zattoni F, Muzzio PC, Zattoni F (2013) Utility of choline positron emission tomography/computed tomography for lymph node involvement identification in intermediate- to high-risk prostate cancer: a systematic literature review and meta-analysis. Eur Urol 63(6):1040-1048. doi:10.1016/j.eururo.2012.09.039

46. Umbehr MH, Muntener M, Hany T, Sulser T, Bachmann LM (2013) The role of 11C-choline and 18F-fluorocholine positron emission tomography (PET) and PET/CT in prostate cancer: a systematic review and meta-analysis. Eur Urol 64(1):106-117. doi:10.1016/j.eururo.2013.04.019

47. Valerio M, Anele C, Charman SC et al (2015) Transperineal template prostate-mapping biopsies: an evaluation of different protocols in the detection of clinically significant prostate cancer. BJU Int. doi:10.1111/bju.13306

48. Siddiqui MM, Rais-Bahrami S, Turkbey B et al (2015) Comparison of MR/ultrasound fusion-guided biopsy with ultrasound-guided biopsy for the diagnosis of prostate cancer. JAMA 313(4):390-397. doi:10.1001/jama.2014.17942

49. Eccles BK, Cross W, Rosario DJ et al (2013) SABRE 1 (surgery against brachytherapy - a randomised evaluation): feasibility randomised controlled trial (RCT) of brachytherapy vs radical prostatectomy in low-intermediate risk clinically localised prostate cancer. BJU Int 112(3):330-337. doi:10.1111/bju.12127

50. Wilt TJ, Brawer MK, Jones KM et al (2012) Radical prostatectomy versus observation for localized prostate cancer. $\mathrm{N}$ Engl $\mathrm{J}$ Med 367(3):203-213. doi:10.1056/NEJMoa1113162

51. Kanthabalan A, Shah T, Arya M, et al (2015) The FORECAST study-focal recurrent assessment and salvage treatment for radiorecurrent prostate cancer. Contemp Clin Trials. doi:10.1016/j.cct.2015.07.004

52. Relton C, Torgerson D, O'Cathain A, Nicholl J (2010) Rethinking pragmatic randomised controlled trials: introducing the "cohort multiple randomised controlled trial" design. BMJ 340:c1066. doi:10.1136/bmj.c1066 